\title{
Editorial on EAIT 2015, Issue 3 "Computers and Education around the World"
}

\author{
Arthur Tatnall ${ }^{1}$ \\ Published online: 16 May 2015 \\ (C) Springer Science+Business Media New York 2015
}

This issue of Education and Information Technologies really does come from 'around the world' with articles from authors in Portugal, Belgium, Ireland, Poland, Malaysia, Greece, USA, Philippines, Nigeria, Australia and Pakistan.

The first article is by Fernando Almeida and Justino Lourenço (Polythenic Institute of Gaya, Portugal), Hiram Bolaert (Artesis Hogeschool Antwerp, Belgium), Shane Dowdall (Dundalk Institute of Technology, Ireland), Piotr Milczarski (University of Lodz, Poland) and is titled: "The WalkAbout framework for contextual learning through mobile serious games". The article notes that learning through games is increasingly gaining acceptance as a valuable training tool within the education and training community. This is due to its simplicity and cost effectiveness, helped by most people preferring playing over learning. This article introduces a novel development framework and a learning process called WalkAbout for contextual learning mobile game systems that enables learners to practice and enhance 21 st century skills, while generating and playing mobile contextual games.

Next comes: "Measuring the effectiveness of blended learning environment: A case study in Malaysia" by Cho Cho Wai and Ernest Lim Kok Seng (Taylor's Business School, Taylor's University, Malaysia). They begin by reminding us that the learning environment has traditionally been associated with the physical presence of classrooms, textbooks, pen-and-paper examinations and teachers, but that today's evolving technology with online learning, teleconferencing, the Internet, Computer Assisted Learning (CAL), Web-Based Distance Learning has rapidly changed the face of education. Their article uses path analysis to focus on a set of quantitative data relating to perceptions of effectiveness and efficiency of blended learning and attitudes towards technology.

The article that follows: "On the value of Second Life for students' engagement in blended and online courses: A comparative study from the Higher Education in Greece" was contributed by Nikolaos Pellas (University of the Aegean, Greece) and

Arthur Tatnall

Arthur.Tatnall@vu.edu.au

1 Victoria University, PO Box 14428, Melbourne 8001, Australia 
Ioannis Kazanidis (Kavala Institute of Technology, Greece). The article looks at threedimensional and multi-user virtual worlds as candidate platforms in Higher education, noting that there is still a paucity of a comparative study on the degree of the students' engagement in constructionist-collaborative learning scenarios. In the reported study, the effects of students' achievements were measured by comparing the degree of students' engagement from two student groups (graduate and undergraduate) enrolled in two different instructional formats (blended/online) held in Second Life (SL) to become learning content developers.

"How digital native learners describe themselves", by Penny Thompson (Oklahoma State University, and Michigan State University, USA) describes interviewing eight university students from the 'digital native' generation to see the connections they saw between technology use and learning, and also their reactions to the popular press claims about their generation. Participants agreed with some of the claims on a surface level but also described a deliberate and strategic approach to managing the distractions of technology in order to pursue their educational goals.

Rex P. Bringula (University of the East, Philippines) then describes a study that attempted to develop valid and reliable Capstone Project Attitude Scales. The article: "Development of capstone project attitude scales" examines scales including the Modified Fennema-Shermann Mathematics Attitude Scales with Usefulness, Confidence and Gender View as the three subscales from a questionnaire answered by 463 students. The study revealed that the measurement model of the revised scales provided a good fit and the constructs were distinct from one another.

The "Impact of a participatory cyber-crime prevention program on secondary school students' attainment in crime prevention concepts in civic education and social studies" discusses cyber-crime in Nigeria. Peter Adewale Amosun (University of Ibadan, Nigeria), Olugbenga Adedayo Ige (Adekunle Ajasin University, Nigeria) and Kim-Kwang Raymond (University of South Australia, Australia) describe the design of a cyber-crime prevention program based on the action research paradigm. Nigeria is considered by many to be among the world's top cyber-crime committing countries. The reported study evaluated the impact of the action cyber-crime prevention program on 218 Nigerian secondary school students' attainment in Civic Education and Social Studies. Their analysis suggests that their action cyber-crime prevention program has a positive effect on students' attainment.

An article by Dimitris Spanos and Alivisos Sofos (University of the Aegean, Greece): "The views and attitudes of students participating in a one-to-one laptop initiative in Greece" reported findings that students who participated in a one-to-one laptop initiative indicated that they have higher motivation, greater interest at school and feel more organised. This was the first such initiative in Greece and examined views and attitudes of the students, finding that students like having the laptop at school and go there with greater pleasure, they consider the classes more enjoyable but they are bothered with technical problems. Differences in the views of boys and girls were considered and found that boys are more adaptable whereas girls appreciate more the learning possibilities of the laptop.

Ecaterina Pacurar (University of Strasbourg, France) and Nargis Abbas (University of Sargodha, Pakistan) next present: “Analysis of French secondary school teachers' intention to integrate digital work environments into their teaching practices", 
investigating the effective use of Digital Work Environment in France. They describe a theoretical framework based on the pedagogical engineering approach that was used to propose a hypothetical model resulting in an explained variable of intention for the pedagogical use of an educational technology. Their results demonstrated that a Digital Work Environment is perceived primarily as a 'communication tool' or as a means to achieve the prescribed uses by the academic institutions.

"Student and in-service teachers' acceptance of spatial hypermedia in their teaching: The case of HyperSea" is an article by George Koutromanos (National and Kapodistrian University of Athens, Greece), Georgios Styliaras (University of Patras, Greece) and Sotiris Christodoulou (Technological Educational Institute of Messolonghi, Greece). Their reported study used the Technology Acceptance Model to investigate the factors that influence student and in-service teachers' intention to use a spatial hypermedia application; the HyperSea, in their teaching. HyperSea is a modern hypermedia environment that takes advantage of space in order to display content nodes and social media pages that can be dragged from the Internet. The results showed that Perceived Usefulness was the most important predictor in their attitude and intention but that only Attitude Towards Use had direct influence on teachers' intentions and perceived usefulness influenced teachers' intention. Perceived ease of use in this study failed to emerge as a significant predictor of teachers' attitude and perceived usefulness.

An article by Sasha A. Reese (Indiana University of Pennsylvania, USA) looks at: "Online learning environments in higher education: Connectivism vs. dissociation". The author notes that over the last decade online education has emerged as a way for students and faculty to collaborate more freely, attain greater flexibility and utilize new media to learn, but that burning debate lies in whether online educational options are harmful to traditional education or offer endless benefits necessary to accommodate a $21^{\text {st }}$ century learner. A balanced online environment should provide a blend of both asynchronous and synchronous opportunities, which promote communication and collaboration among classmates and instructors.

This issue's final article: "Distributed collaborative homework activities in a problem-based usability engineering course" has come from John M. Carroll, Hao Jiang and Marcela Borge (Pennsylvania State University, USA). The article describes how teams of students in an upper-division undergraduate Usability Engineering course used a collaborative environment to carry out a series of three distributed collaborative homework assignments that involved case-based analyses structured using a jigsaw design. For this the students were provided with a collaborative software environment and introduced to a simple model of collaboration. Their study found that although the students were able to use the collaboration model and reported a great variety of benefits and challenges in carrying out the distributed collaborative homework activities, the quality of their collaboration was poor both before and after training.

\section{Arthur Tatnall}

Editor-in-Chief 